\title{
EDUTEC: 12 AÑOS NO SON NADA
}

\section{Presentación}

\author{
Isabel Mํㅗ Solano Fernández \\ Coordinadora del monográfico \\ imsolano@um.es \\ Facultad de Educación \\ Universidad de Murcia
}

Desde hace algunos años, las nuevas tecnologías han pasado a ser un tema constante de análisis y debate en los sectores sociales y de enseñanza, sobre todo en el ámbito universitario. Los que hace unos años huían de la novedad de la tecnología, hoy apuestan por la innovación de los procesos de enseñanza-aprendizaje mediante el uso de las TIC. La Universidad española ha puesto de manifiesto su preocupación por ofrecer una enseñanza más flexible y de calidad, adaptada a las demandas sociales y a las necesidades personales incorporando recursos tecnológicos y en red tanto para la gestión y la investigación, como para la docencia.

Las tecnologías que hace décadas eran vistas con escepticismo han pasado a formar parte hoy de nuestro entorno cultural, social y personal de comunicación e interacción, y se ha comenzado a hablar incluso de la invisibilidad de determinadas tecnologías. Con iniciativas europeas como el programa eLearning y el marco estratégico europeo i2010, las TIC han comenzado a ser consideradas como una oportunidad para incrementar la calidad, la diversidad y efectividad de la educación europea y de los sistemas de enseñanza en general. Podríamos decir que las TIC están de moda, y con ello no queremos decir sólo que se usan más y mejor, sino principalmente que constituyen piezas clave en proyectos de innovación educativa y en investigaciones de diferentes áreas de conocimiento y disciplinas. Como diría una buena amiga, ese complejo de bicho raro que teníamos por dedicarnos a esto de la cacharrería se ha traducido en una tendencia de moda.

Pero para llegar a este momento ha sido necesario un arduo y largo proceso de análisis de las tecnologías, de reflexión de la aplicabilidad didáctica de las mismas, de desarrollo de experiencias de incorporación de las TIC en contextos formales y no formales, de implementación de plataformas de enseñanza en línea, de reflexión sobre 
modelos de enseñanza, de análisis de funcionalidades educativas de las redes, de la inclusión del software social para la configuración de diferentes formas de establecer una relación comunicativa entre los agentes de enseñanza, del desarrollo de experiencias orientadas al conocimiento libre, de la definición de comunidades virtuales de profesionales, etc. Todas ellas son temáticas abordadas en los últimos años de desarrollo de la Tecnología en España desde el punto de vista académico, curricular y científico.

Hoy más que nunca se hace necesario que recordemos el proceso que siguieron las tecnologías en España para ser incorporadas en contextos de enseñanza, así como los profesionales que contribuyeron a su desarrollo. Hace algo más de diez años se creó la Asociación Edutec con el propósito de favorecer el intercambio de experiencias y reflexiones entre diversos profesionales de la Tecnología Educativa, permitiendo así el desarrollo de esta disciplina y de las Nuevas Tecnologías aplicadas a la Educación. Ahora nos reunimos en el monográfico EDUTEC: 12 años no son nada para hacer balance de nuestra andadura, de los orígenes de la Asociación y de sus nuevas líneas de futuro.

En este número especial de la revista electrónica de Tecnología Educativa EDUTEC se incluyen artículos en los que se revisan algunos de los acontecimientos más destacados de este periodo, como la celebración del Congreso Internacional Edutec en sus sucesivas ediciones tanto en España como en Latinoamérica, la publicación de la lista de discusión EDUTEC-L y de la Revista electrónica de Tecnología Educativa EDUTEC, así como de la Comunidad Virtual de Tecnología Educativa EDUTEC-E. Francisco Martínez, presidente de la Asociación, nos muestra los comienzos de Edutec, y lo hace analizando con detenimiento los orígenes de la Tecnología Educativa en España, desde las primeras actuaciones de algunos de sus pioneros hasta los estudios sistemáticos de los fundadores que le otorgaron entidad como disciplina en los curricula de las titulaciones de Educación. En el monográfico se presta atención también a la presencia cada vez mayor que la Asociación está teniendo en América Latina, se incluyen algunas reflexiones sobre lo que ha supuesto este periodo para la Asociación, su evolución, sus principales aportaciones y sus líneas de futuro.

Desde estas páginas, quisiera agradecer a cada uno de los autores de este monográfico sus valiosas aportaciones y reflexiones en torno a los orígenes de la Asociación Edutec. Con este monográfico hemos pretendido realizar una revisión sistemática del camino que ha seguido la Tecnología Educativa en las últimas décadas, tanto desde el punto de vista de la investigación como de la docencia, y de las tendencias de futuro que debería seguir.

Todos los que hemos contribuido a la publicación de este monográfico esperamos que las aportaciones y reflexiones incluidas en él sean de utilidad para entender el pasado 
y el presente de una Asociación que aspira a continuar estando en primera línea de acción y reflexión del desarrollo de la Tecnología Educativa y las Nuevas Tecnologías aplicadas a la Educación en el contexto español, latinoamericano, e incluso europeo. 